\title{
A EFICIÊNCIA DAS SALAS DE RECURSOS PARA ALUNOS COM DEFICIÊNCIA DE APRENDIZAGEM NO MUNICÍPIO DE SÃO GABRIEL-RS.
}

\author{
Vera Lucia da Silva Weber'; Luciana Borba Benetti² \\ ${ }^{1}$ Pós-Graduada em Educação: Interdisciplinaridade e Transversalidade, Unipampa. \\ veralucaweber@hotmail.com \\ ${ }^{2}$ Professora Adjunta da Universidade Federal do Pampa. \\ lucianabenetti@unipampa.edu.br
}

\section{RESUMO}

Esta pesquisa visa compreender como se constitui o programa de Educação Especial denominado Sala de Recursos e seu papel no processo de inclusão de alunos com deficiência/necessidades educacionais especiais no ensino regular do município de São Gabriel-RS, na medida em que essas Salas têm como principal objetivo oferecer AEE - Atendimento Educacional Especializado de forma a contribuir para com a apropriação do conhecimento científico desses alunos e, dessa forma, contribuir para seu processo de inclusão escolar e social. Inicialmente o trabalho faz um breve histórico da educação inclusiva; a seguir, explicita sobre o programa denominado Sala de Recursos, contextualizando-o em nível federal, estadual e municipal com as chamadas Salas de Recursos Multifuncionais. Para a realização deste artigo foi utilizada a abordagem metodológica qualitativa em forma de questionário, para as equipes diretivas dos educandários de ensino do referido município que possuem as salas em questão, pois a educação especial é uma modalidade de educação considerada como um conjunto de recursos e estratégias de apoio, que estejam à disposição de todos os alunos, oferecendo diferentes alternativas de atendimento, prevendo ainda uma rearticulação da educação no sentido de providenciar estratégias e métodos que dêem conta do atendimento ás crianças com necessidades especiais. E que esses instrumentos possam ser absorvidos e utilizados não só pela criança especial, mas por toda a comunidade escolar.

Palavras-chave: Declaração de Salamanca, Salas de Recursos, São Gabriel/RS.

\section{ABSTRACT}

This research aims to understand how the program is called the Special Education Resource Room and its role in the process of inclusion of students with disabilities / special educational needs in mainstream education in the municipality of São Gabriel-RS, to the extent that these rooms have as main objective to offer ESA -Educational Support Services specialist to contribute to the appropriation of scientific knowledge of these students and thus contribute to the process of educational and social inclusion. Initially, the work gives a brief history of inclusive education; then explains about the program called Resource Room, contextualizing it at the federal, state and municipal calls Multifunctional Resource Rooms. To realize this article was a qualitative methodological approach used in the form of a questionnaire for the management teams of education of that county that have the rooms in question, since special education is a form of education considered as a set of resources and support strategies that are available to all students, offering different alternatives of care, providing a further reorganization of education in providing strategies and methods that take account of care to children with special 
needs. And that these instruments can be absorbed and used not only for the special child, but for the whole school community.

Keywords: Salamanca Statement - Rooms Resources - San Gabriel / RS.

\section{INTRODUÇÃO}

O movimento é a primeira manifestação na vida do ser humano, pois desde a vida intrauterina realizamos movimentos com o nosso corpo, no qual vão se estruturando e exercendo enormes influências no comportamento psicomotor.

A partir deste conceito, consideramos que a psicomotricidade é um instrumento riquíssimo que nos proporciona resultados satisfatórios em situações de dificuldades no processo de ensinoaprendizagem.

Segundo Assunção e Coelho (1997, p.108).

A psicomotricidade é a "educação do movimento com atuação sobre o intelecto, numa relação entre pensamento e ação, englobando funções neurofisiológicas e psíquicas". Além disso, possui uma dupla finalidade: "assegurar o desenvolvimento funcional, tendo em vista as possibilidades da criança, e ajudar sua afetividade a se expandir e equilibrar-se, através do intercâmbio com o ambiente humano".

Os movimentos expressam o que sentimos nossos pensamentos e atitudes que muitas vezes estão arquivadas em nosso inconsciente. Estrutura o corpo com uma atitude positiva de si mesma e dos outros, a fim de preservar a eficiência física e psicológica, desenvolvendo o esquema corporal e apresentando uma variedade de movimentos (ASSUNÇÃO e COELHO, 1997).

Através da ação sobre o meio físico com o meio social e da interação como ambiente social, processa-se o desenvolvimento e a aprendizagem do ser humano. É um processo complexo, em que a combinação de fatores biológicos, psicológicos e sociais, produzindo nele transformações qualitativas. Para tanto desenvolvimento envolve aprendizagem de vários tipos, expandindo e aprofundando a experiência individual. O professor deve estar sempre atento às etapas do desenvolvimento do aluno, colocando-se na posição de facilitador da aprendizagem e calcando seu trabalho no respeito mútuo, na confiança e no afeto. Ele deverá estabelecer com seus alunos uma relação de ajuda, atento para as atitudes de quem ajuda e para a percepção de quem é ajudado. Diante disso, percebe-se a importância da dimensão da psicomotricidade no processo de ensino-aprendizagem, pois a mesma está intimamente ligada aos aspectos afetivos com a motricidade, com o simbólico e o cognitivo.

De acordo com Assunção e Coelho (1997 p 108):

A psicomotricidade integra várias técnicas com as quais se pode trabalhar o corpo (todas as suas partes), relacionando-o com a afetividade, o pensamento e o nível de inteligência. Ela enfoca a unidade da educação dos movimentos, ao mesmo tempo em que põem em jogo as funções intelectuais. As primeiras evidências de um desenvolvimento mental normal são manifestações puramente motoras. 
Diante desta visão, as atividades motoras desempenham na vida da criança um papel importantíssimo, em muitas das suas primeiras iniciativas intelectuais. Enquanto explora o mundo que a rodeia com todos os órgãos dos sentidos, ela percebe também os meios com os quais fará grande parte dos seus contatos sociais. Portanto, a educação psicomotora na idade escolar deve ser antes de tudo uma experiência ativa, onde a criança se confronta com o meio. A educação proveniente dos pais e do âmbito escolar, não tem a finalidade de ensinar à criança comportamentos motores, mas sim permite exercer uma função de ajustamento individual ou em grupo (FONSECA e OLIVEIRA, 2009).

As atividades desenvolvidas no grupo favorecem a integração e a socialização das crianças, portanto propicia o desenvolvimento tanto psíquico como motor. Os movimentos, as expressões, os gestos corporais, bem como suas possibilidades de utilização, recebem um destaque especial em nosso desenvolvimento fisiológico e psicológico (FONSECA, 2005).

Com base neste contexto, percebemos a importância das atividades motoras na educação, pois elas contribuem para o desenvolvimento global das crianças. Entretanto, as crianças passam por fases diferentes uma das outras e cada fase exige atividades propicias para cada determinada faixa etária. A psicomotricidade precisa ser vista com bons olhos pelo profissional da educação, pois ela vem auxiliar o desenvolvimento motor e intelectual do aluno, sendo que o corpo e a mente são elementos integrados da sua formação. Nessa perspectiva, percebe-se a importância da educação física nos dias atuais levando a perceber que há diversas possibilidades de garantir a formação integral do aluno por meio do movimento humano. Desta forma, a busca por ferramentas de auxílio à aprendizagem escolar tem se tornado uma constante na perspectiva multidisciplinar. O desenvolvimento psicomotor é importante como forma de detectar problemas de aprendizagem. A consideração à psicomotricidade nas aulas de Educação Física poderá auxiliar na aprendizagem escolar, contribuindo para o fenômeno cultural que consiste em ações psicomotoras exercidas sobre o ser humano de maneira a favorecer comportamentos e transformações (ASSUNÇÃO e COELHO, 1997).

A psicomotricidade nas aulas de Educação Física atua como uma ferramenta de auxílio na aprendizagem. É, sobretudo, visando à possibilidade de compreensão da importância de inserir conhecimentos da psicomotricidade nas aulas, com o intuito de auxiliar na aprendizagem global dos alunos. Esse conhecimento abrange a relação do desenvolvimento intelectual (relações com a aprendizagem no contexto escolar) e desenvolvimento motor tais como: coordenação motora fina; estruturação espacial; orientação temporal; lateralidade; estruturação corporal.

A referente pesquisa é de campo e composta por questões relacionadas à aprendizagem e ao conhecimento do Decreto Lei e da Declaração de Salamanca. Os professores devem procurar novo saberes científicas e novas concepções educacionais para que possa atender a diversidade de seus alunos. Sabe-se que as (DA) quase sempre se manifestam agregadas a outros comprometimentos, como prejuízos de ordem emocional (as crianças podem apresentar sentimentos de exclusão, de rejeição, de insucesso, ansiedade, agressividade) comportamental (como isolamento, revolta), problemas afetivo social (tristeza), alterações de processos cognitivos (DA dos processos simbólicos da fala, leitura, escrita, aritmética), problemas psicomotores, problemas de atenção e problemas de memória (dificuldades de memorização visual e auditiva) possuindo ou não relação com a escola. O Município de São Gabriel - RS possui atualmente vinte e seis (26) escolas municipais, divididas em ensino fundamental e escolas infantis, atendendo aproximadamente cinco mil alunos (5000), destas vinte e seis escolas apenas três possui em seu PPP (Projeto Político Pedagógico) e consequentemente em seus Regimentos Escolares a viabilidade de salas de recursos multifuncionais, as mesmas estão localizadas geograficamente em pontos estratégicos no município. Sendo uma Central, outra em bairro e a outra na periferia. Duas 
delas possuem espaço físico e materiais adequados e a outra possui espaço físico adequado e os materiais em aquisição, devido ao pouco tempo que começou o funcionamento da sala em questão. Frente a esta explanação justifica-se esta pesquisa, que tem por finalidade; Investigar a eficiência da psicomotricidade no desenvolvimento intelectual dos escolares que evidenciam dificuldades de aprendizagem no seu processo de escolarização nas salas de recursos, no Município de São Gabriel-RS.

\section{REFERENCIAIS TEÓRICOS}

O fortalecimento da inclusão da pessoa com necessidades educativas especiais na escola comum foi assinalado pela Declaração de Salamanca (1994), reafirmando que o movimento pedagógico, além das características democráticas, deverá ser pluralista, não garantindo apenas o acesso, mas a permanência do aluno nos diversos níveis de ensino e respeitando fundamentalmente sua identidade social, ressaltando que as diferenças são normais e a escola deverá considerar essas múltiplas diferenças, promovendo as adaptações necessárias, que atendam as necessidades de aprendizagem de cada educando no processo educativo. Esse documento fortalece que "os programas de estudos devem ser adaptados às necessidades da criança e não o contrário. As escolas deverão, por conseguinte, oferecer opções curriculares que se adaptem às crianças com capacidade e interesses diferentes" (Declaração de Salamanca, 1994; e o Decreto Legislativo no. 186/2008). Assim sendo, a escola deve oferecer programas educacionais flexíveis, contribuindo para a promoção de desafios, de forma a superar as necessidades grupais ou individuais, compreendendo e reorganizando ações educativas que garantam aprendizagem de novos conhecimentos. Para que se efetivem ambientes escolares inclusivos, novas reflexões devem ser realizadas no âmbito da comunidade escolar, a fim de definir estratégias de ação, participação e organização do ensino, garantindo e melhorando o atendimento aos educandos com dificuldades de aprendizado, combatendo atitudes discriminatórias e construindo uma sociedade inclusiva, na qual as oportunidades sociais sejam garantidas a todos os cidadãos. Com base no Decreto citado acima, pode-se afirmar que a psicomotricidade possui um impacto positivo no pensamento, no conhecimento e na ação, nos domínios cognitivos e na vida em geral do ser humano. Entretanto, o indivíduo fisicamente educado vai para uma vida ativa, saudável e produtiva, criando uma integração mais segura e adequada ao desenvolvimento do corpo, da mente e do espírito. Assim, as atividades afetivas, psicomotoras e sociopsicomotoras, constituem-se em fator de equilíbrio na vida das pessoas, expressando-se na interação entre o espírito e o corpo, a afetividade e a energia, o indivíduo e o grupo, promovendo a totalidade do ser humano.

$\mathrm{Na}$ grande maioria das vezes, as crianças com DA são vistas como menos engajadas em suas tarefas escolares que os seus colegas sem dificuldades, sendo que muitas dessas crianças também se deparam com problemas de socialização que podem prosseguir ao longo da vida escolar. Acredita-se que a sala de recursos quando utilizada de forma apropriada pode ajudar a potencializar o desenvolvimento cognitivo e a aprendizagem dos alunos. Para tanto se faz necessário que os docentes que atuam nesse ambiente, bem como os que encaminham seus discentes tenham um saber especifico para que o principal personagem desse processo, o aluno, não possa sair prejudicado.

A sala de recursos é um espaço diferenciado no qual o professor tem por objetivo promover a aprendizagem aos alunos com DA através de brinquedos e jogos lúdicos. Segundo 
Duarte (1986), Sala de recursos é considerada uma sala "[...] provida de material e equipamentos apropriados para atendimento das necessidades específicas de alunos excepcionais". Atualmente, nas escolas municipais do município de São Gabriel, está ocorrendo à implementação de salas de recursos multifuncionais, com a finalidade de atender maior número de crianças com as mais diferentes deficiências físicas e intelectuais.

De acordo com Alves (2006, p. 14):

A sala de recursos multifuncionais é, portanto, um espaço organizado com materiais didáticos, pedagógicos, equipamentos e profissionais com formação para o atendimento às necessidades educacionais especiais. No atendimento, é fundamental que o professor considere as diferentes áreas do conhecimento, os aspectos relacionados ao estágio de desenvolvimento cognitivo dos alunos, o nível de escolaridade, os recursos específicos para sua aprendizagem e as atividades de complementação e suplementação curricular. A denominação sala de recursos multifuncionais se refere ao entendimento de que esse espaço pode ser utilizado para o atendimento das diversas necessidades educacionais especiais e para desenvolvimento das diferentes complementações ou suplementações curriculares. Uma mesma sala de recursos, organizada com diferentes equipamentos e materiais, pode atender, conforme cronograma e horários, alunos com deficiência, altas habilidades/superdotação, dislexia, hiperatividade, déficit de atenção ou outras necessidades educacionais especiais. Para atender alunos cegos, por exemplo, deve dispor de professores com formação e recursos necessários para seu atendimento educacional especializado. Para atender alunos surdos, deve se estruturar com profissionais e materiais bilíngües. Portanto, essa sala de recursos é multifuncional em virtude de a sua constituição ser flexível para promover os diversos tipos de acessibilidade ao currículo, de acordo com as necessidades de cada contexto educacional.

Segundo Fredes "[...] a ludicidade é importantíssima para a construção de bases sólidas para a impulsão do processo de aprendizagem" (2009, p. 40).

Muitos estudos e pesquisas revelam que a brincadeira influencia no processo de ensino aprendizagem, favorecendo o processo de aquisição da linguagem e pensamento lógico, proporcionando saúde física, mental e social. Desenvolve também as potencialidades das crianças e estabelece vínculos positivos entre aluno e professor. O lúdico instiga o aprender, prevenindo dessa forma problemas de aprendizagem possibilitando às crianças o desenvolvimento de suas habilidades e potencialidades. Permitindo que a mesma construa e descubra o mundo que a cerca através de suas próprias vivências dando significado ao seu aprendizado. Macedo, Petty e Passos (2005) fazem uma reflexão acerca da importância de se analisar o aspecto lúdico nos processos de ensino e aprendizagem como sendo uma das principais condições para o desenvolvimento.

Os autores afirmam que cuidar da dimensão lúdica na escola permite que as crianças sejam atores e responsáveis se suas próprias ações.

Os autores citados acima abordam o conceito de desenvolvimento e aprendizagem. No qual afirmam que o desenvolvimento "... refere-se a um processo construtivo que, ao se voltar para dentro, incluir, ao mesmo tempo amplifica-se, desdobra-se para fora" (p.10), e a aprendizagem "... do mesmo modo que desenvolvimento expressa um novo conhecimento, espacial e temporalmente determinado" (p.10). Ou seja, para os autores desenvolvimento e aprendizagem são duas formas de conhecimento, interdependentes, indissociáveis e complementares um ao outro. A criança aprende e desenvolve com seus pares, brincadeiras e jogos a fim de desenvolver suas habilidades e suas emoções. 
Segundo os autores, brincar é de suma importância para o desenvolvimento, é envolvente e interessante. É brincando que as crianças interagem atividades físicas psicomotoras e fantasiosas. Para a criança a brincadeira se dá pelo simples prazer de brincar, sem se ter em mente um objetivo ou justificativa para tal atividade. Discutem ainda a ideia de que o jogo permite e beneficia a aprendizagem, sendo um sucedâneo do brincar.

\section{FUNDAMENTAÇÃO}

A educação inclusiva se caracteriza como processo de incluir os portadores de necessidades especiais ou com distúrbios de aprendizagem na rede regular de ensino, em todos os seus graus, pois nem sempre a criança que é portadora de necessidades especiais (deficiente), apresenta distúrbio de aprendizagem, ou vice versa, então todos esses alunos são considerados portadores de necessidades educativas especiais Fonseca (1991) descreve os tipos de deficiência e suas características gerais:

[...] a criança com paralisia cerebral apresenta essencialmente um problema de envolvimento neuromotor. Do mesmo modo, a deficiência mental apresenta uma inferioridade intelectual generalizada como denominador comum. Por outro lado, na criança deficiente visual ou auditiva, o problema situa-se ao nível da acuidade sensorial. No que respeita à criança emocionalmente perturbada esta apresenta um desajustamento psicológico como característica comportamental predominante.

Para essas crianças é necessário que se desenvolva uma prática educacional mais específica no sentido de ampliar as suas capacidades. Para cada deficiência é enfatizado um tipo de cuidado no trabalho educativo. Sendo assim, a psicomotricidade quando aplicada adequadamente poderá e deverá fazer a diferença entre os educandos, educadores e comunidade escolar. "Nessa perspectiva a Declaração de Salamanca", retomou a discussão sobre educação especial na perspectiva de minimizar os abismos entre os humanos, partindo do pressuposto de "Educação para Todos", que vem sendo defendido mundialmente pela UNESCO.

Glat (1998, p.45) afirma que:

Apesar da integração dos portadores de deficiência ser o discurso dominante na Educação especial no mundo todo, direcionando programas e políticas educacionais e de reabilitação, esses indivíduos, mesmo aqueles inseridos no sistema regular de ensino ou em empregos competitivos, continuam, na grande maioria dos casos socialmente isolados dos seus colegas não deficientes. (...) o problema não é, em sua essência, de natureza legal ou ocupacional, mas sim de natureza relacional, e somente sob esse prisma pode ser melhor compreendido, e quem sabe, minimizado. (...) a questão da integração dos deficientes envolve antes de mais nada o relacionamento entre essas pessoas e os considerados normais'.

A inclusão é consequência de uma escola de qualidade, isto é uma escola capaz de perceber cada aluno como um enigma a ser desvendado. O que percebe é que a criança com deficiência, na escola inclusiva nas salas de recursos multifuncionais denuncia a falência do sistema escolar, o que se verifica é que os professores não sabem o que fazer, por mais que tenham boa vontade e competência, pois para os professores o medo fala mais alto, ou seja, "o medo de errar", o que 
denuncia uma formação continuada inadequada ou inexistente do professor; outro ponto de dificuldade é a falta de relacionamento da escola com a família, a escola ainda encontra-se muitas vezes fechada à comunidade para discussão da perspectiva inclusiva. Essa entre tantas outras situações inadequadas no sistema brasileiro escolar tem representado apenas a abertura das portas das escolas para educação inclusiva. Acredito que isto é muito pouco embora signifique uma nova atitude.

Dentro deste contexto observa-se que muitos portadores de deficiência vivem em forma de isolamento social, pois vivem dentro da estrutura familiar e estas costumam segregá-los, fazendo com que eles fiquem esquecidos, ao invés de incluí-los. A crítica ao sistema de ensino brasileiro, é que o princípio da integração é utilizado, mas para constituir classes especiais em escolas regulares, ou seja, apóia-se a educação inclusiva, mas as crianças portadoras de deficiência e as ditas normais continuam excluídas das oportunidades de integração, convivência e inclusive de afeto.

As escolas inclusivas devem atender a todos, a Declaração de Salamanca diz que:

O princípio fundamental das escolas inclusivas consiste em que todos os alunos devam aprender juntos, sempre que possível, independentemente das dificuldades e das diferenças que apresentem. As escolas inclusivas devem reconhecer e satisfazer as necessidades diversas dos seus alunos, adaptando aos vários estilos e ritmos de aprendizagem, de modo a garantir um bom nível de educação para todos, através de currículos adequados, de uma boa organização escolar, de estratégias pedagógicas, de utilização de recursos e de uma cooperação com as respectivas comunidades. É preciso, portanto, um conjunto de apoios de serviços para satisfazer o conjunto de necessidades especiais dentro da escola.

Cabe então à escola criar estratégias para incluir esses alunos com necessidades especiais no ensino regular, reconhecendo as necessidades individuais de cada um. È importante que a mesma junto aos seus profissionais aceite as novas estratégias de ensino. Diferente de muitos outros países a inclusão no Brasil ainda está engatinhando, o sucesso escolar é não só um mérito dos alunos, mas também dos professores, que de uma maneira ou de outra deverão criar metodologias e estratégias de ensino para as crianças com necessidades especiais, mas em alguns casos para que esses professores consigam atingir os seus objetivos é necessário que se tenha um serviço de apoio funcionando, a LDB no artigo 58 quando diz que:

10 Haverá quando necessário serviço de apoio especializado, na escola regular, para atender às peculiaridades da clientela de educação especial; 200 atendimento educacional será feito em classes, escolas ou serviços especializados, sempre que, em função das condições específicas dos alunos, não for possível a sua integração nas classes comuns de ensino regular.

A educação física, há décadas atrás apresentava um modelo em que o físico (corpo), a aptidão física e desempenho eram o mais importante, desprezando muitas vezes os aspectos sociais, cognitivos e afetivos. O relevante dentro das aulas de educação física era o esporterendimento, ou seja, o aluno deveria apresentar um bom desempenho e habilidades não só nas aulas, mas também nos jogos e em determinadas modalidades esportivas, levando o aluno a ser quase um atleta. Desta forma apresentava um modelo excludente, por apresentar aulas com métodos de ensino por repetição, o que tornava essas mais monótonas, sem uma preocupação com a participação de todos os alunos. Com os avanços teóricos na Educação, e também na Educação Física, novas abordagens vêm surgindo, e a LDB e os Parâmetros Curriculares Nacionais, 
vêm contribuindo para levar a disciplina a um lugar de destaque na "formação de cidadãos críticos, participativos e com responsabilidades sociais". Porém, com todos estes avanços ainda está enraizado um modelo biológico de homem, e muitos profissionais ainda estão preocupados com o corpo e suas capacidades fisiológicos, mantendo-se assim ainda muito seletivos. A LDB em seu artigo 26 no parágrafo 3ㅇ diz que a Educação física está integrada a proposta pedagógica da escola, é componente curricular da educação básica, ajustando-se às condições da população escolar. Então como pode a Educação física partir de um modelo seletivo? Seria ela capaz de ter um comportamento excludente potencializado?

Segundo os PCNs, que é um documento que traz subsídios para os profissionais da área de educação física, onde a proposta curricular é incluir os temas transversais nas aulas, que são Ética, Saúde, Meio Ambiente, Orientação Sexual, Pluralidade Cultural e Orientação para Trabalho e Consumo, o professor deve estimular uma reflexão, e assim contribuir para uma visão crítica da disciplina dentro do meio social, assim sendo a educação física reflete uma mudança no seu objetivo onde um deles é formar cidadãos e não formar atletas, tendo visto que um de seus principais objetivos no ensino fundamental é que os alunos sejam capazes de: Participar de atividades corporais, estabelecendo relações equilibradas e construtivas com os outros, reconhecendo e respeitando características, físicas e de desempenho de si próprio e dos outros, sem discriminar por características, pessoais, físicas, sexuais ou sociais. Com isso as aulas de Educação física devem propiciar aos alunos através de atividades corporais uma atitude construtiva com os portadores de necessidades educativas especiais, possibilitando uma atitude de respeito, aceitação e solidariedade. Nessas condições podemos salientar a importância da psicomotricidade na educação física para detectar e ajudar os alunos com os diversos transtornos mencionados.

A Psicomotricidade Pode ser usada como parâmetro para observar as condições psicomotoras dos indivíduos avaliados, haja vista que quando há um desenvolvimento cognitivo inadequado, provavelmente há um atraso no desenvolvimento motor. Estes instrumentos são utilizados tanto para detectar possíveis déficits psicomotores, quanto auxiliam na elaboração de um planejamento para a estimulação psicomotora quando tais déficits são apontados.

De acordo com Ministério da Educação e do Desporto (MEC) e Secretaria de Educação Especial (MEC/SEE, 1993), a psicomotricidade é a integração das funções motrizes e mentais, sob o efeito do desenvolvimento do sistema nervoso, destacando as relações existentes entre a motricidade, a mente e a afetividade do indivíduo.

A função motora, o desenvolvimento intelectual e o desenvolvimento afetivo estão intimamente ligados no indivíduo, e a psicomotricidade quer justamente destacar a relação existente entre a motricidade, a mente e a afetividade, facilitando a abordagem global da criança por meio de uma técnica (MEUR e STALES, 1989).

Sara Pain (1979), citada por Conceição (1984), distingue corpo e organismo, dizendo que um organismo é comparável a um aparelho de recepção programada, que possui transmissores capazes de registrar certos tipos de informação e reproduzi-las, quando necessário. Já o corpo não se reduz a esse aparato somático, quando atravessado pelo desejo e pela inteligência, compõe uma corporeidade, um corpo que aprende que pensa e atua.

O organismo bem estruturado é a base para a aprendizagem, conseqüentemente, as deficiências orgânicas podem condicionar ou dificultar esse processo.

A aprendizagem inclui sempre o corpo, porque inclui o prazer, e este está no corpo, sem o qual o prazer desaparece. A participação do corpo no processo de aprendizagem se dá pela ação (principalmente nos primeiros anos) e pela representação. 
O organismo constitui a infraestrutura neurofisiológica de todas as coordenações, e que torna possível a memorização. Um organismo enfermo ou deficiente pode prejudicar a aprendizagem na medida em que afeta o corpo, o desejo, a inteligência.

\section{METODOLOGIA}

Para a realização deste artigo foi utilizada a abordagem metodológica qualitativa, (GASKELL e GEORGE, 2003) que envolve a obtenção de dados descritivos em contato direto com a situação estudada e por questionários direcionados à Secretaria Municipal de Ensino (SEME) e para as equipes diretivas das escolas envolvidas. Em primeiro lugar, o Termo de Consentimento Livre e Esclarecido (TCLE), foi apresentado ao Senhor Secretário Municipal de Educação de São Gabriel RS, para a busca de informações sobre as escolas municipais que aderiram as salas de recursos multifuncionais conforme a Legislação Vigente da Escola Aberta do Brasil e pela Declaração de Salamanca, sobre princípios, políticas e práticas na área das necessidades educativas especiais. 0 Município de São Gabriel-RS possui vinte e seis (26) escolas distribuídas em escolas de educação infantil e ensino fundamental, e, apenas três dessas implantaram as salas de recursos. Para assegurar sigilo, essas escolas foram mencionadas no presente artigo como Escola A, Escola B e Escola C.

Após o aceite do TCLE, foram entrevistadas as equipes diretivas das escolas que possuem as salas de recursos e salas de recursos multifuncionais. Foram elaboradas dez (10) questões, sendo sete (7) objetivas, com opção de respostas de sim ou não, uma questão com resposta mais elaborada sobre a frequência dos alunos nas salas de recursos, e duas questões com respostas diferenciadas onde dependeu da estrutura física, profissionais disponíveis e a clientela atendida. A maioria das questões formuladas foi baseada no Decreto de Salamanca e no Decreto Legislativo sobre a implantação e aplicabilidade dos mesmos. As outras questões foram formuladas sobre a quantidade de alunos em atendimento e as deficiências atendidas pelas referidas escolas em suas salas de recursos.

\section{RESULTADOS E DISCUSSÃO}

A questão de número um (01) e a de número dois (02) dizem respeito à aplicabilidade dos artigos do decreto no. 6.571/2008; e o decreto legislativo no. 186/2008, com fundamento no Parecer CNE/CEB n‥ 13/2009.

Questão número um (01): O aluno com deficiência tem direito à educação em classe comum em seu turno, junto aos seus colegas de turma e ele também tem direito ao Atendimento Educacional Especializado (AEE) no contra turno?

Questão número dois (02): O Atendimento Educacional Especializado se dará nas salas de recursos da própria escola ou da escola mais próxima. No ato de matrícula, os agentes de educação especial já organizam os encaminhamentos dos alunos da Educação Especial para as salas de recursos existentes?

$\mathrm{Na}$ avaliação das respostas foi constatado o conhecimento das equipes diretivas sobre a aplicabilidade dos Decretos mencionados, sendo assim, as três escolas responderam afirmativamente, totalizando cem por cento (100\%), conforme as figuras de número um (01) e dois (02). 


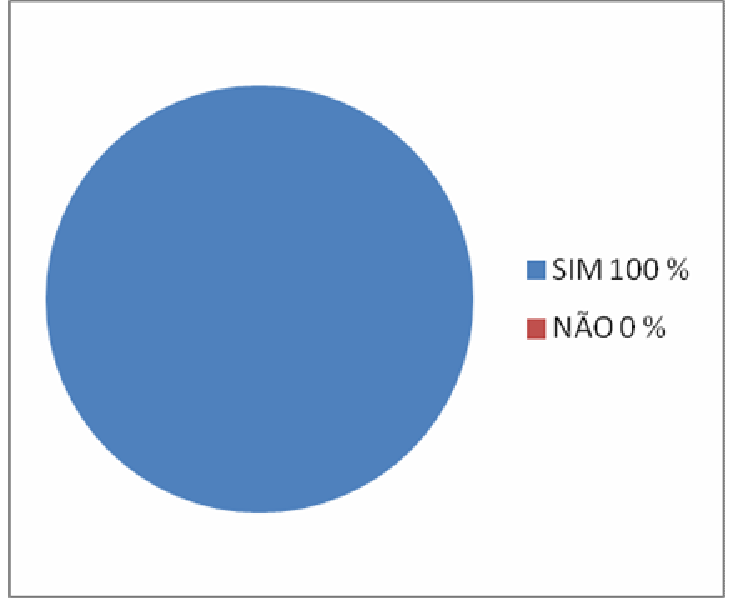

Figura 01: Resultado obtido com a aplicação da questão 01

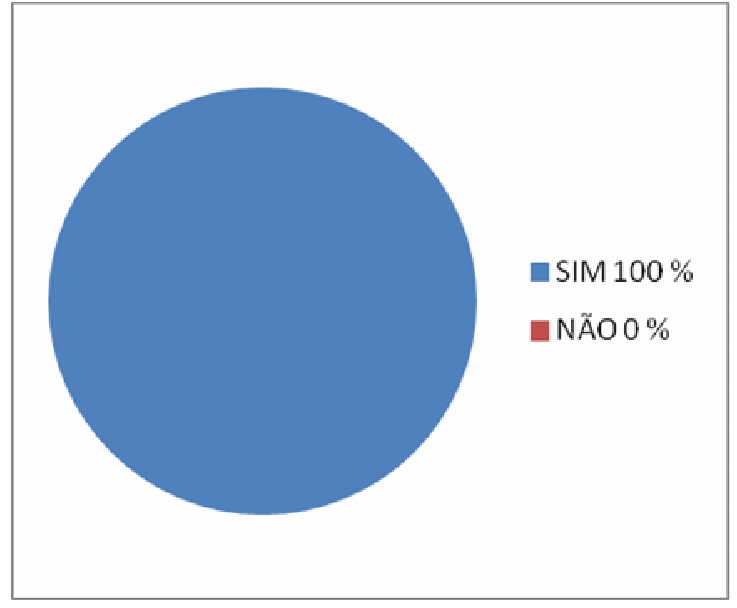

Figura 02: Resultado obtido com a aplicação da questão 02

Questão número três (03): O aluno com deficiência, transtornos globais do desenvolvimento e altas habilidades também podem ser encaminhados para as salas de recursos por solicitação dos diretores das escolas?

A questão de número três foi formulada com o intuito de avançar na construção de escolas inclusivas sendo necessário que cada sistema de ensino dê sequência à investigação, referente à inclusão na educação, considerando os indicadores de acesso, permanência e progresso dos alunos, aprofundando sua compreensão acerca do processo de escolarização, tendo como referência o acolhimento, o planejamento colaborativo, o acesso ao currículo e o atendimento às necessidades educacionais especiais. Na avaliação da resposta foi constatado que as equipes diretivas das três escolas responderam afirmativamente, conforme a figura de numero três (03).

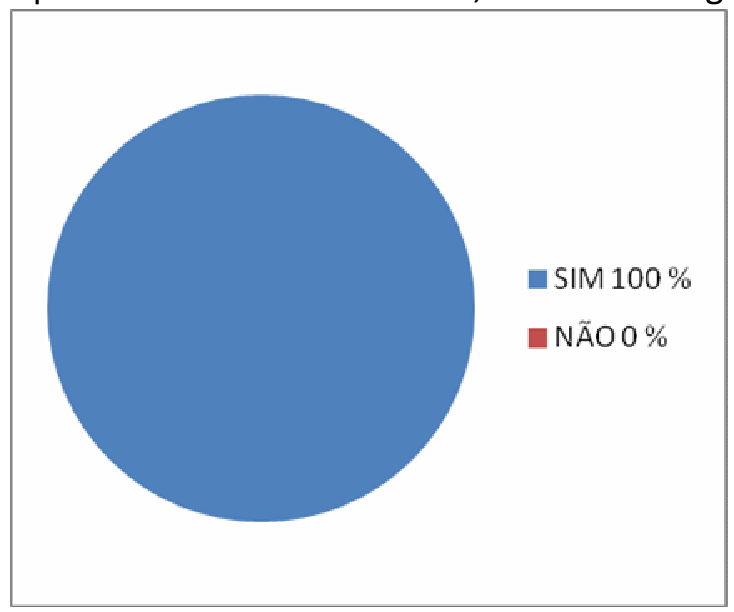

Figura 03: Resultado obtido com a aplicação da questão 03

Questão número quatro (04): Toda criança, jovem ou adulto público alvo da Educação Especial, matriculado, na rede municipal, possui este direito?

A questão de número quatro diz respeito ao direito e a oportunidade aos alunos inclusos, vindo a enriquecer a educação em nosso País, colocando-nos diante dos novos compromissos que 
vem sendo assumidos, em nível federal, estadual e municipal, para a garantia do acesso e qualidade no processo educacional. Na avaliação da resposta foi constatado que as equipes diretivas das três escolas responderam afirmativamente, conforme a figura de número quatro (04).

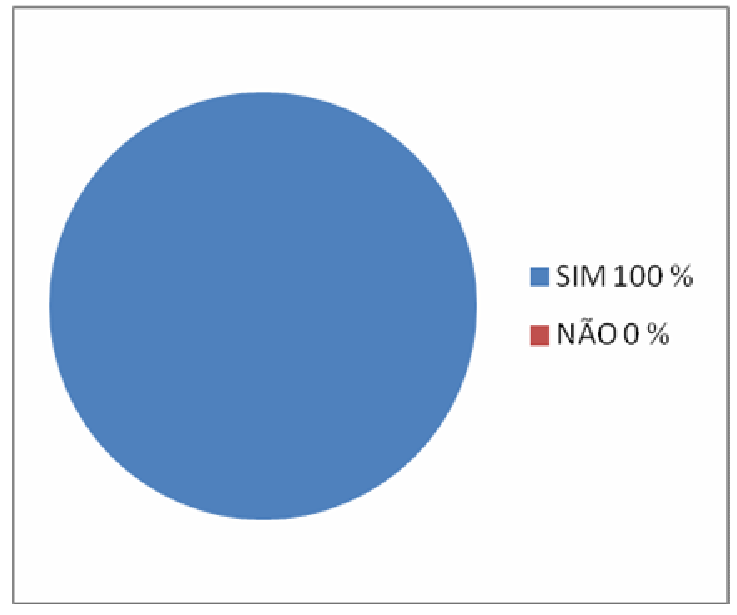

Figura 04: Resultado obtido com a aplicação da questão 04

Questão número cinco (05): Caso a aluno tenha (ou não) um laudo que defina a deficiência e/ou transtorno, os agentes de educação especial podem ser acionados por meio de Relatório sobre o Aluno enviado à SEME com a devida solicitação de avaliação e estudo do caso para a educação especial?

A questão de número cinco (05) foi formulada apartir dos dados que, a Secretaria Municipal de Educação do Município de São Gabriel-RS adota, ou seja, um modelo de inclusão escolar em que diferentes modalidades de atendimento e suporte educacional da Educação Especial são mantidas, de acordo com as necessidades identificadas de cada aluno. Na avaliação da resposta foi constatado que as equipes diretivas das três escolas responderam afirmativamente, conforme a figura de número cinco (05).

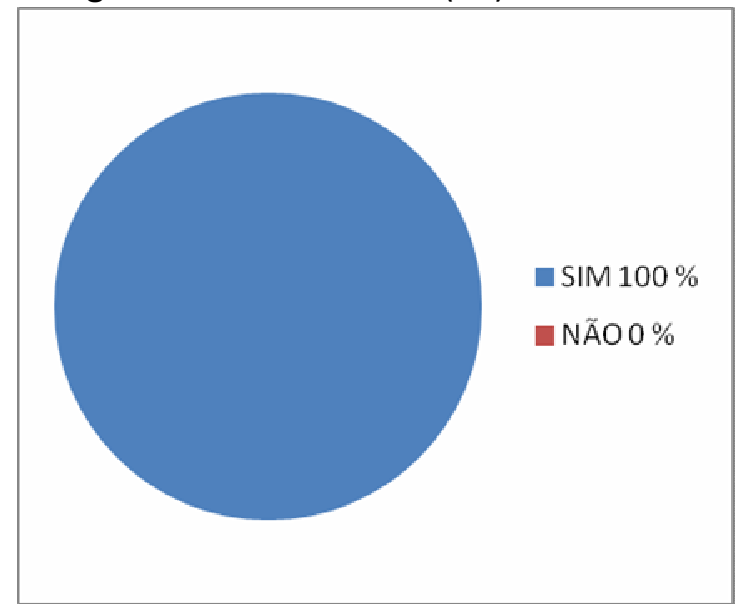

Figura 05: Resultado obtido com a aplicação da questão 05 
Questão número seis (06): Os agentes de educação especial e os professores de AEE não são médicos, portanto, não fecham quadros diagnósticos. Deste modo, solicitam aos profissionais especializados na área da saúde esclarecimentos quanto ao quadro, quando há necessidade?

Questão número sete (07): A parceria educação e saúde são sempre bem vindas e necessárias, resguardadas as áreas de atuação e as responsabilidades de cada um. Feita a analise e o acompanhamento do caso (apartir de dados da escola, da família e dos profissionais da saúde) o agente de educação especial definirá a escola com sala de recursos mais próxima e mais adequada e redigira o encaminhamento do aluno enviando o documento em duas vias, uma delas para a sala de recursos e a outra para a classe comum do aluno?

As questões de números seis (06) e sete (07) tratam especificamente do respaldo entre SEMEESCOLA-SAUDE, pois caso o aluno tenha (ou não) um laudo que defina a deficiência e/ou transtorno, os agentes de educação especial podem ser acionados por meio de relatório sobre o mesmo enviado à SEME com a devida solicitação de avaliação e estudo do caso para Educação Especial. Na avaliação da resposta foi constatado que as equipes diretivas das três escolas responderam afirmativamente, conforme a figura de número seis (06) e número sete (07).

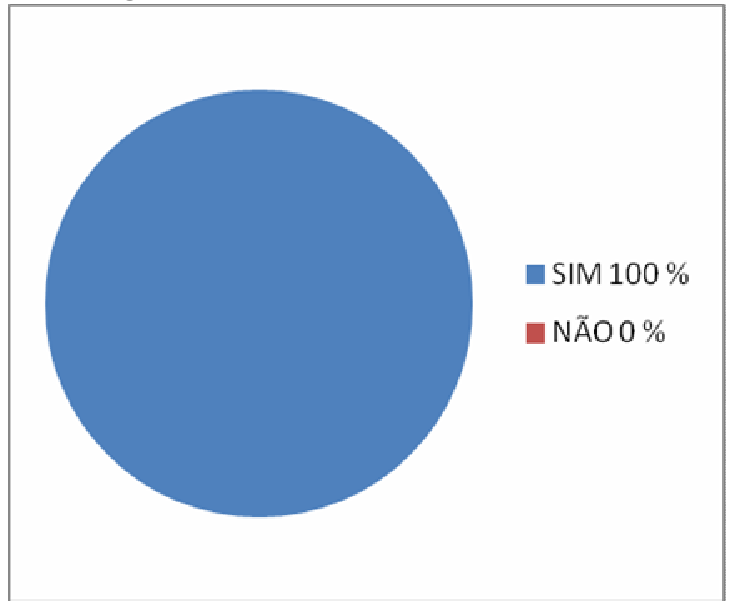

Figura 06: Resultado obtido com a aplicação da questão 06

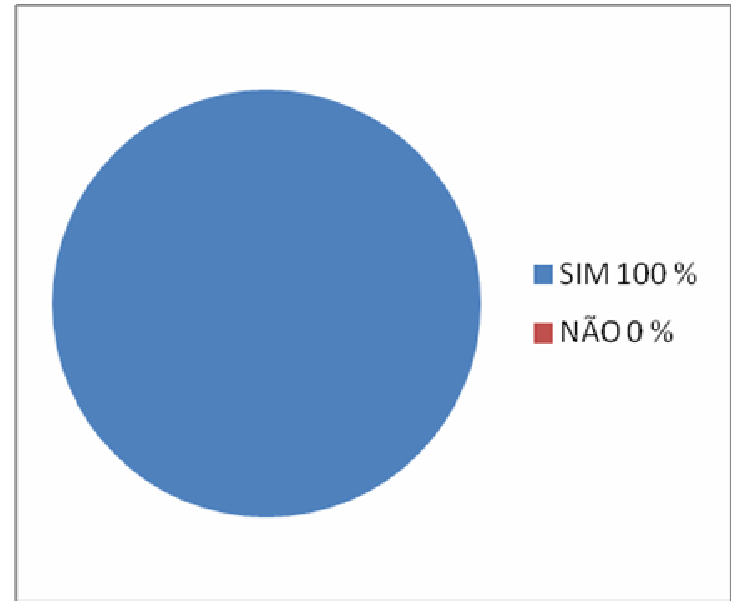

Figura 07: Resultado obtido com a aplicação da questão 07

Questão número oito (08): Quantos estudantes são atendidos na sala de recursos?

A questão de número oito (08) é sobre a demanda de alunos atendidos. Como era esperada, a resposta foi diferenciada, devido à localização geográfica das escolas e pela quantidade de alunos de outros educandários pesquisados, ressalvo que em nenhum dos educandários pesquisados existem alunos de outros estabelecimentos de ensino, pois são todos matriculados em suas escolas de origem, e atendidos nas salas de recursos dos mesmos. recursos?

Questão número nove (09): O que fazer se a família optar por não levar o aluno à sala de

Nesse questionamento as visitas serão importantes para mostrar a presença da Educação Especial, buscar nos professores e na direção da escola os aliados para o convencimento da importância da sala de recursos.

$\mathrm{Na}$ avaliação da resposta conforme a figura nove (09) foi constatada que, nenhuma das escolas respondeu corretamente, pois a resposta correta seria a escolha das três alternativas ( $a, b$ e c) presentes no questionário, devido a ser um dos itens da Declaração de salamanca e as alternativas a 
serem respondidas também fazem parte da mesma. Indicando assim que as equipes conhecem o básico do Decreto, quanto à funcionalidade, já as questões que dizem respeito à verdadeira aplicabilidade e o amparo legal que os educandários devem ter, pela resposta da questão de número nove (9), verifica-se que a Declaração de Salamanca não é de total conhecimento das equipes diretivas dos educandários pesquisados. Sendo assim interpretadas as alternativas sugeridas na questão em percentuais.

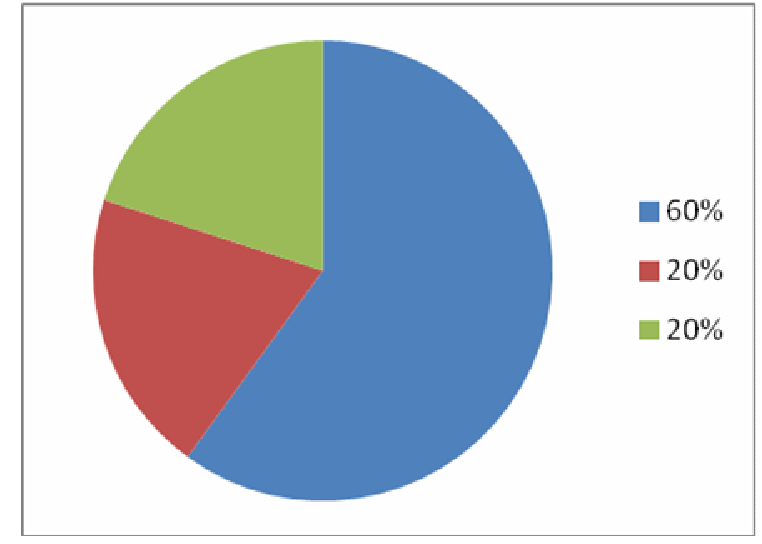

FIGURA 09: Resultados obtidos as escolas A, B e C.

- $60 \%$, o professor de sala de recursos precisa quebrar a resistência do AEE convidando a família e o aluno para conhecer a sala para que o responsável converse com os outros pais e observe os benefícios do atendimento.

- $20 \%$, fazer um bom atendimento experimental com o aluno, começar aos poucos com horários mais adequados (para que seja possível atender ao horário do deslocamento, medicamentos dos mesmos).

- $20 \%$, mesmo que o pai do aluno expresse que deseja desistir da sala de recursos, o aluno ainda assim continua sendo aluno da escola e do AEE.

Questão de número dez (10): Quais desses transtornos são mais evidenciados nos alunos?

A questão de número dez especifica quais os transtornos diagnosticados e quantos alunos são atendidos nos três educandários de ensino. As figuras abaixo demonstraram os dados obtidos. Sendo assim interpretados: Escolas Pesquisadas totalizando cem por cento (100\%) e serão identificadas por Escola A, Escola B e Escola C.

Transtornos Evidenciados: Deficiência Intelectual (DI), Deficiência Auditiva (DA), Deficiência Visual (DV), Deficiência Física (DF), Transtornos Globais do Desenvolvimento (TGD) e Altas Habilidades (AH). 


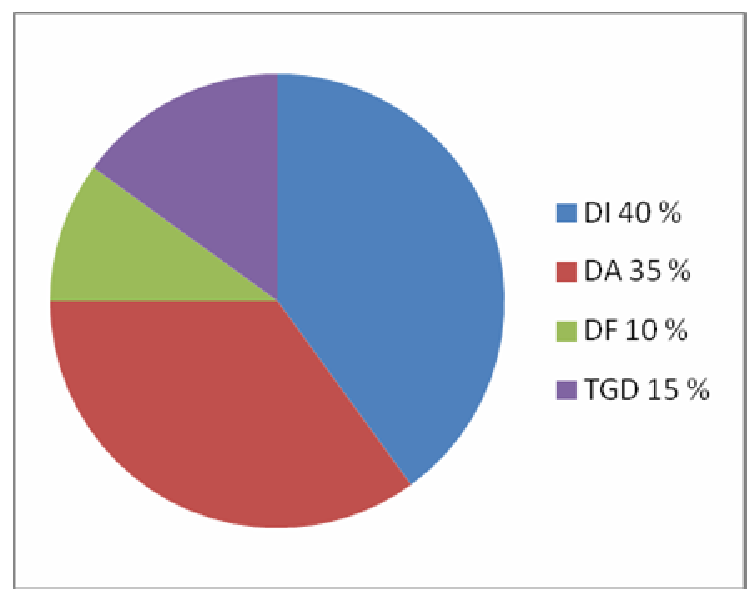

Figura 10 a: Escola $\mathrm{A}$

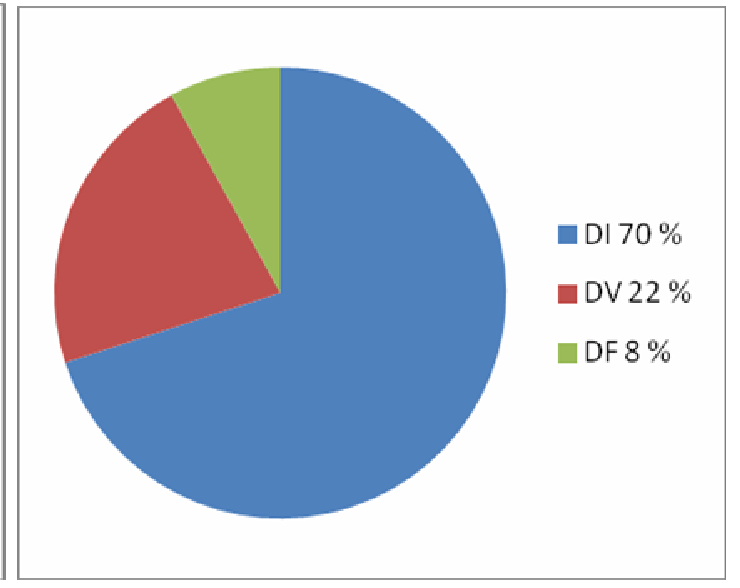

Figura 10 b: Escola B

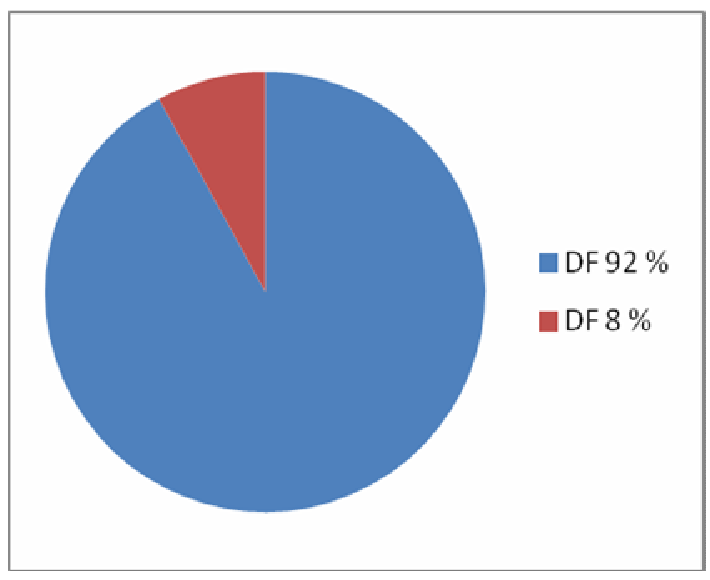

Figura 10 c: Escola C

Considerando o total dos alunos atendidos nas Salas de Recursos em São Gabriel, cinquenta e seis (56), o transtorno em maior evidencia é a deficiência intelectual, que corresponde a expressões como insuficiência, falta, falha, carência, imperfeição associadas ao significado de deficiência (do latim deficientia) que por si só não definem nem caracterizam um conjunto de problemas que ocorrem no cérebro humano, e leva seus portadores a um baixo rendimento cognitivo, muitas vezes sem afetar outras regiões ou funções cerebrais, essa definição é da Organização Mundial de Saúde (OMS). Com base na definição pela OMS e pela aplicabilidade do decreto e da declaração de Salamanca, foi pesquisado junto às escolas quantos dos alunos com o transtorno intelectual passaram por avaliação de profissionais competentes da área, pois tanto no decreto como na declaração, está nítido o encaminhamento que o aluno com suposta deficiência intelectual deverá ter antes do encaminhamento às salas de recursos. Decreto $n$ ‥ 6.571/2008; e o Decreto Legislativo №. 186/2008, e com fundamento no Parecer CNE/CEB no. 13/2009, que diz em um dos seus artigos (as pessoas com esse transtorno, são dependentes de cuidadores e necessitam de atendimento multiprofissional, incluindo: médico, fisioterapeuta/terapeuta ocupacional, musicoterapeuta, fonoaudiólogo, psicólogo, pedagogo (psicopedagogia) entre outros, a fim de minimizar os problemas decorrentes da deficiência). 
Dos alunos com DI, totalizando trinta e sete (37), apenas vinte (20) possuem laudo de fonoaudiólogo, psicólogo ou neurologista. O restante possui apenas a indicação da professora regente das salas comuns de aula.

\section{CONSIDERAÇÕES FINAIS}

Ao término deste trabalho revelaram-se as possibilidades de inclusão de pessoas com deficiência no ensino regular, e principalmente ao nível de ensino público, no município de São Gabriel-RS, abrindo o questionamento sobre as estratégias que podem ser adotadas para enfrentar as resistências (conscientes e inconscientes) de professores e diretores dos educandários de ensino regular. Considera-se que o processo de inclusão está longe da perfeição, pois os professores que atuam em salas de recursos tiveram apenas alguns dias de capacitação, não importando se esse profissional era atuante no currículo por atividade, ou mesmo se acreditava em uma escola inclusiva.

É importante ser definido o que é afinal a Educação Especial da qual a inclusão, agora, é linha mestra. A educação especial no Brasil segue os pressupostos formulados pela LDB (Lei de Diretrizes e bases), lei no. 9394, de 20 de dezembro de 1996, que define a educação especial como modalidade de educação escolar, oferecida preferencialmente na rede regular de ensino, para pessoas com necessidades educacionais especiais. A educação especial é uma modalidade de educação considerada como um conjunto de recursos educacionais e de estratégias de apoio que estejam à disposição de todos os alunos, oferecendo diferentes alternativas de atendimento, prevendo ainda uma rearticulação da educação no sentido de providenciar estratégias e métodos que dêem conta do atendimento ás crianças com necessidades especiais. E que esses instrumentos possam ser absorvidos e utilizados não só pela criança especial, mas por toda a comunidade escolar. Estas diretrizes de inclusão estão presentes nas leis e estatutos atuais que de alguma forma abordam a questão escolar. Estão presentes na Constituição Federal, nas leis Estaduais e Municipais, no estatuto da criança e do Adolescente e na LDB. Estes documentos são unânimes na prerrogativa de uma educação para todos e de que crianças com necessidades educacionais especiais devam ser inseridas preferencialmente na rede regular de ensino. Portanto, é obrigação da escola em receber crianças com necessidades especiais como também ter espaço físico adequado, profissionais competentes, atuantes e capacitados para receberem a demanda do alunado especial.

Dentro da expressiva quantidade de escolas municipais de São Gabriel-RS, são poucos os educandários de ensino que aderiram em seu PPP e consequentemente em seus Regimentos Escolares a implantação das salas de recursos. Sendo assim a linha de pensamento deverá ser mudada, tanto na diagnosticagem da clientela, quanto na escolha dos profissionais que atuam nessas salas. Esses devem ser apoiados por equipes especializadas bem como, um professor de educação física, pois, quanto mais cedo houver um diagnóstico e mais precoce for à intervenção melhores serão os resultados na aprendizagem, identificando precocemente lesões e intervir nas denominadas: Avaliação do Desenvolvimento e Exame Neuropsicomotor Evolutivo (psicomotricidade). Dar-se aí o papel das escolas e dos professores, de levar os alunos a aprender a viver socialmente, pois a escola é um espaço de transformação social, seja ela para crianças portadoras de necessidades especiais ou não. Esses espaços de educação devem promover relações recíprocas e dialéticas, eliminando estigmas, rótulos e etiquetas que classificam comportamentos. 
Somente assim, serão trabalhadas as reais necessidades de sua clientela e realizadas mediações no processo de aprendizagem com atividades desafiadoras, que estabeleçam conflitos interiores e promovam a verdadeira inclusão social.

Há, pois aí, uma experiência a ser lida com carinho e se possível aprimorada por todos os que querem todas as crianças aprendendo e ensinando juntas, sem qualquer tipo de discriminação. Como já disse e repito: a inclusão não é impossível, embora ainda tenhamos muitos obstáculos a superar, mas sempre que possível pela força de coletivos dedicados a modificar os paradigmas e ampliar os horizontes, que podem se tornar mais BELOS.

\section{REFERÊNCIAS BIBLIOGRÁFICAS}

ALVES, Denise de Oliveira. Sala de Recursos Multifuncionais: espaços para atendimento educacional especializado. Ministério da Educação, Secretaria de Educação Especial. Brasília, 2006. Antares: Nobel, 1986. Boletim da Federação Nacional das APAEs. InformAPAE. ANO VII. Fevereiro e Abril de 2001.

BOSSA, Nadia A. Dificuldades de aprendizagem: O que são? Como tratá-las?

BRASIL. Estatuto da Criança e do Adolescente. Lei no 8.068 de 13 julho de 1990.(ementa). Diário Oficial da União de 13 de julho de 1990.

. Lei de Diretrizes e Bases da Educação Nacional. Lei no 9.394 de 20 de dezembro de 1996. Diário

Oficial da União de 23 de dezembro de 1996.

CONCEIÇÃO, J. F. et al. Como entender o excepcional deficiente mental. Rio de Janeiro: Rotary Club, 1984. p.23- 24

Declaração de Salamanca e Linha de Ação sobre Necessidades Educativas Especiais. (1994, Salamanca). Brasília: CORDE, 1997.

FEDERAÇÃO NACIONAL DAS APAES. Coleção Educação Especial: Fundamentos. 1993; v1. p. 177 FERREIRA, I. N. Caminhos do aprender: uma alternativa educacional para a criança portadora de deficiência mental. Rio de Janeiro: I.N. Ferreira, 1998.p.15 a 25. , Júlio Romero. A exclusão da diferença: a educação do portador de deficiência. Piracicaba: UNIMEP, 1993. FONSECA, V. Educação Especial: programa de estimulação precoce - uma introdução às idéias de Feuerstein. 2a ed. rev. aum. Porto Alegre: Artes Médicas. 1995, p.26-27.

V. Manual de Observação psicomotora: Significação psiconeurológica dos fatores psicomotores. Porto Alegre: Artes Médicas. 1995.

Vitor da. Educação Especial: Programa de intervenção precoce. Porto Alegre: Cortez, 1996. FREDES, Maria Elizabete Pereira. A ludicidade como estratégia na prevenção das integração. Brasília: Ministério da Educação - Secretaria de Educação Especial, julho/agosto de 1989. MACEDO, Lino. O lúdico nos processos de desenvolvimento e aprendizagem escolar. In: João Alberto da. (orgs). Psicopedagogia em movimento. Pelotas: EDUCAT, 2009.

, Lino de; PETTY, Ana Lúcia Sícoli; PASSOS, Norimar Chritie. Os jogos e o lúdico na aprendizagem escolar. Porto Alegre: Artmed, 2005.

PIAGET, Jean. O Nascimento da inteligência na criança. RJ, Zahar, 1975.

STAINBACK, Susan e STAINBACK, William. Inclusão: um guia para educadores. Porto Alegre: Artes Médicas, 1999. 